\section{AB0073 EARLY MARKERS OF BONE - CARTILAGE RESORPTION IN PATIENTS WITH RHEUMATOID ARTHRITIS}

D. Rekalov, N. Rozdolska. Rheumatology, Zaporizhzhia Regional Clinical Hospital, Zaporizhzhia, Ukraine

Background: Systemic disorganisation of connective tissue with early metabolic disorder of its matrix is an inherent characteristic feature of rheumatoid arthritis (RA). The determination of the key extracellular matrix molecules in patients with early RA can adequately characterise a metabolism of connective tissue, stage of its destruction and the duration.

Objectives: to evaluate the significance of bone-cartilage resorption as an integral indicator of inflammatory-destructive processes in patients with early RA Methods: We included 168 patients with early RA. The quantitative content and qualitative composition of glycosaminoglycans (GAG) in blood serum and excretion of GAG in urine were evaluated. Oxiproline (OP) and its fractions (free $O P$ ), protein-bound $(\mathrm{OPp})$ and hydroxyproline were determined in serum and urine. The presence of antibodies to the cyclic citrullinated peptide (ACPA) was studied, as well as the $\mathrm{C}$-terminal telopeptides of serum collagen I (CTX).

Results: We identified the results of excretion of GAGs in urine depending on disease activity. And according to our data, in patients with low inflammatory process (IP) the level was $-6.31 \pm 1.09 \mathrm{mg} / \mathrm{g}$ of creatinine $(\mathrm{CR})$; moderate IP -5.21 $\pm 1.20 \mathrm{mg} / \mathrm{g}$ of $\mathrm{CR}$, and high disease activity $-6.53 \pm 0.96 \mathrm{mg} / \mathrm{g}$ of CR. All these results were significantly higher in comparison with the control group by $55.9 \%$, $29.1 \%$ and $67.7 \%$, respectively. It means that GAG excretion rate did not depend on the stage of disease activity in patients with early RA, although even with a minimal IP it was significantly higher than normal. At the same time, the fractional composition of excreted GAGs in the urine in RA patients varied, as evidenced by a significant decrease in the sulfated GAGs content by $35 \%$ compared to the control group, although the differences between the groups were statistically unreliable.

CTX also proved to be 2.86 times higher than the level of healthy persons in whom the indicated index was $0.15 \mathrm{ng} / \mathrm{ml}$.

In addition to a statistically significant increase of serum concentration of OP as compared to practically healthy persons, the qualitative composition of its fractions also changes, as evidenced by a significant elevation of OPp by $167.81 \%$. No significant differences were found in the evaluation of OPfree and hydroxyproline

Abstract AB0073 - Table 1. Baseline demographic and clinical characteristics of RA patients, $(n=168)$

\begin{tabular}{|c|c|c|}
\hline \multicolumn{2}{|c|}{ Characteristic } & Value \\
\hline \multicolumn{2}{|c|}{ Age, years } & $47,52 \pm 13,05$ \\
\hline \multirow{2}{*}{ Gender } & Male, n (\%) & $59(35)$ \\
\hline & Female, n (\%) & $109(65)$ \\
\hline \multicolumn{2}{|c|}{$\begin{array}{l}\text { Duration of symptoms, } \\
\text { months }\end{array}$} & $13,74 \pm 6,2$ \\
\hline \multicolumn{2}{|c|}{ DAS28 (ESR) } & $5.9(4.6-6.3)$ \\
\hline \multicolumn{2}{|c|}{ ACPA positive, $\mathrm{n}(\%)$} & $102(61)$ \\
\hline \multicolumn{2}{|c|}{ Using GCs, n (\%) } & $18(11)$ \\
\hline \multicolumn{2}{|c|}{ Using NSAIDs, n (\%) } & $122(73)$ \\
\hline \multicolumn{2}{|c|}{ HAQ, points } & $1.3(0.7-1.9)$ \\
\hline \multicolumn{2}{|c|}{ RF positive, n (\%) } & $83(49)$ \\
\hline
\end{tabular}

Conclusions:

1. Progression of RA is accompanied by a progressive loss of the main functionally significant components of the extracellular matrix and manifested by a significant increase in the concentrations of proteoglycans and oxyproline.

2. The level of C-terminal telopeptides of type I of serum collagen - was elevated even in patients with early RA, indicating the activity of bone resorption processes.

3. The concentration and qualitative composition of blood serum GAGs adequately reflect the clinical symptoms of RA, being a sensitive integral test that reliably indicates the severity of inflammatory and destructive changes.

\section{REFERENCE:}

[1] Garnero P, Gineyts E, Christgau S, et al. Association of baseline levels of urinary glucosyl-galactosyl-pyridinoline and type II collagen C-telopeptide with progression of joint destruction in patients with early rheumatoid arthritis. Arthritis Rheum 2002;46:21-30.

Acknowledgements: None

Disclosure of Interest: None declared

DOI: 10.1136/annrheumdis-2018-eular.1970

\section{AB0074 DAILY EXERCISE SUPPRESSES ACUTE PRO- INFLAMMATORY CYTOKINE EXPRESSION SYSTEMICALLY AND IL-1B LOCALLY IN A MURINE MODEL OF GOUT}

N.A. Young ${ }^{1}$, K. Jablonski ${ }^{1}$, B. Sandoval ${ }^{1}$, A. Kalyanasundaram ${ }^{2}$, P. Harb ${ }^{1}$, J. Hampton ${ }^{1}$, W. Jarjour ${ }^{1}$, N. Schlesinger ${ }^{3}{ }^{1}$ Rheumatology and Immunology; ${ }^{2}$ Physiology and Cell Biology, The Ohio State University Wexner Medical Center, Columbus; ${ }^{3}$ Rheumatology, Rutgers Robert Wood Johnson Medical School, New Brunswick, USA

Background: Recent gout clinical practice recommendations/guidelines released by the ${ }^{A C R}$ (2012) and the ${ }^{A C P}(2017)$ do not address exercise as an interventional strategy; in contrast, the 2016 EULAR gout recommendations suggest that regular physical activity might decrease the excess mortality associated with chronic hyperuricemia. Referencing animal studies performed nearly a half century ago, many rheumatologists recommend resting the involved joints during an acute attack. However, recent evidence has demonstrated the anti-inflammatory effects of exercise in patients with rheumatic disease.

Objectives: The purpose of this study was to investigate the effects of exercise intensity on an immunological level in an animal model of gout by characterising pro-inflammatory cytokine expression.

Methods: BALB/C-Tg(NFKB-RE-luc)-Xen mice were exercised daily by treadmill walking $\left(45 \mathrm{~min} /\right.$ day) at low intensity $\left(35 \% \mathrm{VO}_{2} \mathrm{max}\right)$, moderate intensity $(55 \%$ $\mathrm{VO}_{2}$ max), and high intensity ( $\left.75 \% \mathrm{VO}_{2} \mathrm{max}\right)$. Following the 2 week training period, monosodium urate (MSU) crystal-mediated arthritis was induced by intra-articular injection of MSU crystals $(0.5 \mathrm{mg})$ into the tibio-tarsal joint (ankle). At 16 hours post-MSU crystal injection, tissue was collected for immunohistochemistry (IHC) and both serum and synovial aspirates were processed to measure cytokine levels.

Results: Infiltrates consisted primarily of neutrophils and macrophages, as determined by IHC. The inflammatory responses were significantly reduced with low and moderate exercise when compared to either high intensity training or mice that were not exercised. Electrochemiluminescence detection assays quantifying the expression of a panel of pro-inflammatory cytokines showed that IL-2, IL-4, IL5 , IL-10, and IFN- $\gamma$ were not detectable in the serum of MSU crystal-injected mice at levels greater than un-injected male/female controls. Furthermore, IL-12, CXCL1, TNF- $\alpha$, and IL- 6 expression was elevated in the serum with MSU crystal injection compared to un-injected counterparts, but this response was suppressed with low, moderate, or high intensity exercise training and undetectable in synovial aspirates. Conversely, IL-1 $\beta$ was not induced relative to un-injected controls systemically in the serum, but was increased locally in synovial aspirates. IHC staining of the ankle joint region for IL-1 $1 \beta$ confirmed this observation and further demonstrated a significant inhibition with low and moderate exercise relative to both high intensity training and non-exercised controls.

Conclusions: Our results demonstrate that daily exercise can have a measurable effect systemically in reducing pro-inflammatory cytokine expression in MSU crystal-mediated arthritis. Moreover, high-intensity exercise can suppress proinflammatory cytokine expression systemically, however, only low/moderate training suppressed the localised inflammatory response. Collectively, these data suggest a paradigm shift; emphasising physical activity in gout patients is potentially efficacious and warrants further investigation.

\section{REFERENCES:}

[1] Khanna D, et al. Arthritis Care Res 2012;64:1447.

[2] Richette P, et al. Ann Rheum Dis 2017;76:29.

[3] Dorwart BB, et al. Arthritis Rheum 1974;17:563.

Acknowledgements: Support provided by Ironwood Pharmaceuticals, Cambridge MA 02142

Disclosure of Interest: None declared

DOI: 10.1136/annrheumdis-2018-eular.4711 